\title{
Correction to: Nitric Oxide-Induced Regulation of Plant Developmental Processes and Abiotic Stress Responses
}

\author{
Lekshmy Sathee, Hari Singh Meena, Sandeep B. Adavi, \\ and Shailendra K. Jha
}

\section{Correction to:}

Chapter 16 in: M. Hasanuzzaman et al. (eds.), Plant Abiotic Stress Tolerance, https://doi.org/10.1007/978-3-030-06118-0_16

The chapter was inadvertently published with an error, the titles of chapter 16 as is somehow matching with already published chapter (no. 14) in a book entitled "Reactive Oxygen Species in Plants: Boon Or Bane - Revisiting the Role of ROS" with almost the same title. The editors now prefer to replace the title to "Nitric oxide-induced regulation of plant developmental processes and abiotic stress responses" and the same has been updated.

The updated online version of this chapter can be found at https://doi.org/10.1007/978-3-030-06118-0_16 